\title{
Foreign Exchange Reserves and Inflation in Pakistan: Evidence from ARDL Modelling Approach
}

\author{
Imran Sharif Chaudhry \\ Department of Economics, Bahauddin Zakariya University Multan, Pakistan \\ E-mail: imranchaudhry@bzu.edu.pk \\ Mohammad Hanif Akhtar \\ Department of Finance and Accounting, College of Business Administration, Prince Sultan University \\ P.O.Box: 66833, Riyadh, 11586 Kingdom of Saudi Arabia \\ E-mail: mhakhtar@fnm.psu.edu.sa \\ Khalid Mahmood \\ Department of Economics, Bahauddin Zakariya University Multan Pakistan \\ E-mail: khalidmahmoodbzu@gmail.com \\ Muhammad Zahir Faridi \\ Department of Economics, Bahauddin Zakariya University Multan, Pakistan \\ E-mail: zahirfaridi4u@yahoo.com
}

\begin{abstract}
Interest in detection of factors considered responsible for uneven fluctuations in steady state growth of world economies is long standing. There has been an explosion of theoretical literature and empirical evidences which think about compassionate to resolve the issue. Hike in prices of goods and services and foreign exchange are two important aspects which are blamed for such bumpy vacillation in economic growth of the world economies like all other political, social and economic factors. It is true that both factors have special significance for economic growth, but inquiry about internal relationships of the above mentioned both variables still has research thirst. The novelty of this research paper is that it provides the empirical evidence regarding the relationships between foreign exchange reserves and inflation, focusing on Pakistan's experience since 1960. We used the Auto Regressive Distributive Lag Model (ARDL) proposed by Pesaran et al. (2001) in order to investigate the order of co-integration between inflation and foreign exchange reserves through bound testing approach, and also use the OLS estimation to determine the long run relationship. Through this econometric technique, we traced out the nature of relationship and speed of adjustment in the concerned variable due to fluctuations in the level of foreign exchange reserves. Empirical results indicate that the rise in foreign exchange reserves leads to lower the rate of inflation in Pakistan during the study period.
\end{abstract}

Keywords: Inflation, Foreign Exchange, ARDL Estimation, GDP Deflator, Error correction, Pakistan

\section{Introduction}

In the empirical literature many studies claim that inflation is a key economic variable for policy makers, researchers and investors. Around the world no one could refute its matchless position especially in monetary policy determination. So due to worldwide dramatic changes in the inflation and its exceptional position, in recent years research is concerned more with the aspects of inflation. Changes in price levels are caused by national factors like supply shock such as bad harvests, the monopoly of producers, and increase in factors cost, scarcity of raw material, and depreciation/devaluation of domestic currency etc. The change in general price levels may also be caused by excessive or disproportional demand for example increase in population, decline in real income and so forth. But in the current world's economic scenario it is observed that the national factors are not exclusively responsible for inflation, international factors like hike in oil products prices, financial assistance from abroad, and changes in volume and rate of foreign exchange etc. may be to blame for such hike in domestic price level.

In this respect, the study regarding the nature and intensity of relationship between foreign exchange reserves and inflation rate is also a hot issue for researchers especially in those economies where above said variables have uneven and rapid fluctuations. In the modern era the factors like foreign exchange rate and foreign exchange reserves play critical role in economic stability, especially in case of small open economy like Pakistan. The reason is that the bumpy and rapid variations in foreign exchange rate and in its level affect the profitability of entrepreneurs and multinational corporations directly and indirectly. And as a result change in supply of goods and services play a significant role for inflation variations. In case of Pakistan, experience of last few decades of currency devaluation or depreciation has affected our foreign exchange reserves significantly. And such variations in foreign exchange reserves also have an effect on the prices of goods and services. It means that foreign exchange reserves or its level adjusts quickly to the inflation rate in Pakistan. So in this background we have endeavored to investigate the nature and intensity of such connection between foreign exchange reserves and inflation rate. The novelty of this research paper is that it analyzes the relationships between changes in level of foreign exchange reserves and rate of inflation in Pakistan. To asses the direction of relationship between foreign exchange reserves and rate of inflation in Pakistan, we 
directly regressed the reduced form relationship equation through most reliable and recent econometric technique known as ARDL approach and OLS method.

Khan and Qayyum (2007) find that exchange rate is co-integrated with (WPI) price level in Pakistan. Nieh and Chung (2005) and Rahman and Hossain (2003) conclude that the stable exchange rate help the enterprises in investment. Parikh and Williams (1998) bring to a close that fluctuations in exchange rate may have significant impact on prices, unemployment and quantity output. Eatzaz and Ali (1999) probe that relationships between inflation and exchange rate are not unidirectional and simple. In the short run, the effect of inflation on devaluation is greater than the devaluation on inflation and movement in exchange rate generally driven by price inflation in Pakistan. Research undertaken in Pakistan by Ahmed and Ram (1991); Bilquees (1988); Hassan and Khan (1994) and Khan and Qasim (1996) provides reliable evidence that the domestic price level reacts significantly but gradually to devaluation. Meiselman (1975) looks into the connection between international reserves and inflation and find the direct association between changes in international reserves and inflation. Heller (1976) investigates the association between international reserves and world wide inflation and shows that change in international reserves positively affect the world wide inflation through change in monetary base and money supply. Genberg and Swoboda (1977) and Parkin (1977) also probe the nature of correlation between above discussed variables and get the consistent results with Meiselman (1975) and Heller (1976) finale. They conclude that the increase in national money supplies prompted by the international reserves enlargement ultimately have positive impact on national inflation. Khan (1979) finds that it was the growth in international reserves that augment or enlarge the level of inflation. In other words we can say that Mr. Khan Results were consistent with the quantity theory of money approach extended to the international economy. Haastrecht and Pelsser (2008) studied the relationship between the Generic Pricing of foreign exchange, inflation and stock options. Utami and Inanga (2009) tested Fisher effect theory considering yearly and quarterly data on inflation, rate of interest and exchange rate of four countries for the period 2003-2008. They found that interest rate differential and changes in exchange rate are positively and significantly related. Prasertnukul et. al (2010) examined that inflation targeting caused a fall in exchange rate volatility in Asian countries.

The main rationale of this study is empirical scrutiny of the nature of relationship between targeted variables in Pakistan, through ARDL a recent estimation technique, as well as the examination that either it is a short run phenomenon or change in the foreign exchange reserves also affect the inflation rate in long span of time. The second objective of this paper is to probe whether in Pakistan there is typical positive association between foreign exchange reserves and inflation rate (as discussed in literature) or in accordance with our hypothesis (negative correlation between focused variables) in Pakistan. The Third purpose of this study is provision of empirical evidences for those countries that have identical foreign exchange reserves conditions and other economic circumstances and also want to get rid from the problems associated with inflation rate. The paper is organized as follows. After a brief theoretical introduction, section 1 outlines the basic hypothesis which we develop regarding the relationship between focused variables in Pakistan. Section 2 presents Data, Model and the Econometric Methodology, Section 3 is based on empirical examination and analysis of results. And section 4 gives us conclusion and policy recommendations.

\section{The Basic Hypothesis}

It is our primary hypothesis that there is a negative connection between foreign exchange reserves and rate of inflation in Pakistan. Changes in foreign exchange reserves in Pakistan indirectly and inversely affect the rate of inflation. We know that an increase in foreign exchange reserves enhance the monetary base, and presence of stable money multiplier ultimately will have a direct increase in national money supply. Then increase in the national money supplies in turn has an impact on national inflation rate channels via supply changes. Usually increase in monetary base through increase in foreign reserves tends to boost up the aggregate demand of economy. But the case of developing country like Pakistan (importer of less elastic goods and services) is a little bit different than typical behavior. The reason is that Pakistan is an agrarian and less developed country. Its imports are based on approximately inelastic items (oil products, pesticides, fertilizers, medicine, machinery, and food products etc.). It means more or less these imports are compulsory for the survival of the economy. Increase in foreign exchange reserves leads to the enhancement of the monetary base which in turn leads to bigger import of oil, machinery and other raw material. As a result needless increase in productive capacity decreases profits of entrepreneurs and prices of products. Consequently there is reduction in national inflation rate, and vice versa. Another important transmission mechanism links with the agricultural production. Because Pakistan is an agricultural country, through reduction in foreign exchange reserves agriculture products are affected at all levels resulting is decline in agricultural raw material and oil products imports, which in turn is observed in the form of supply shock and higher level of food and core inflation, and vice versa.

\section{Data, Model and Econometric Methodology}

\subsection{Data}

This study analyzes the impact of foreign exchange reserves on inflation rate in Pakistan by using the annual time series statistics from 1960 to 2007, so the total number of observations is 48 . All the statistics are taken from International Financial Statistics. Foreign Exchange reserves is measured in Million US \$, and GDPD (Gross Domestic Product Deflator) is used here as proxy of inflation. We used logarithm transformation of both variables for econometric estimation. 


\subsection{The Model}

To examine the Foreign Exchange Reserves - Inflation rate long run relationships in Pakistan we develop the following econometric model for estimation,

$$
(G D P D)_{t}=\beta_{0}+\beta_{1}(F E)_{t}+\varepsilon_{t}------------------(1)
$$

Here (GDPD) is Gross Domestic Product Deflator (a proxy of inflation rate), and (FE) is stands for Foreign Exchange reserves, at a certain period of time $t ; \beta 0$ is the constant; and $\varepsilon t$ is the stochastic disturbance term. The Foreign Exchange reserves and Inflation rate correlation is determined by the size of beta. To examine the relationships between focused variables study employs the autoregressive distributed lag model (ARDL) suggested by Pesaran et al, (2001), for co-integration investigation (time series data) and error correction (short run) analysis. We use variables in natural logarithm form to asses the significance of Foreign Exchange reserves on inflation rate in Pakistan. So the log transformation of model is as follow:

$$
\ln (G D P D)_{t}=\beta_{0}+\beta_{1} \ln (F E)_{t}+\varepsilon_{t}---------------(2)
$$

In case of more than unity value of concerned beta or slop coefficient (elasticity) rate of inflation will be more sensitive and elastic with the change in foreign exchange.

\subsection{Econometric Methodology}

\subsubsection{Unit Root Estimation}

In order to investigate the level of integration this study makes use of standard tests like ADF (Augmented Dicky Fuller) and DF-GLS (Dicky Fuller Generalized Least Square). Due to less reliability of ADF for small size data (Dejong et al. 1992, Sollice and Harris 2003, Shahbaz et al. 2008) we also use the DF-GLS for scrutiny of co-integration between above mentioned variables. Dejong et al. 1992 and Harris 2003 summarized that some time ADF committing type 1 and type 2 error when samples size are small. Then for more reliability we use DF-GLS as well as ADF test.

The Dicky-Fuller Generalized Least Square de trending test developed by Elliot et al. (1996) and followed by Ng-Perron (2001). On of the assumption that there is need to test the order of integration of variable Xt, Elliot et al. (1996) enhance the power of ADF test by de trending criteria and DF-GLS test is based on null hypothesis $H 0: \delta=0$ in the regression:

$$
\Delta X_{t}^{d}=\delta^{*} X_{t-1}^{d}+\delta_{1}^{*} \Delta X_{t-1}^{d}+\ldots \ldots \ldots+\delta_{p-1}^{*} \Delta X_{t-p+1}^{d}+\eta_{t}
$$

Where $\mathrm{X}_{\mathrm{t}}^{\mathrm{d}}$ is the de trended series and null hypotheses of this test is that $\mathrm{X}_{\mathrm{t}}$ has a random walk trend, possibly with drift as follows.

$$
X_{t}^{d}=X_{t}-\hat{\varphi}_{0}-\hat{\varphi}_{1} t-----------------------(4)
$$

Actually, two hypotheses are proposed.

(1) $X_{t}$ is stationary about a linear time trend and

(2) It is stationary with a non zero mean, but with no linear time trend.

Considering the alternative hypotheses, the DF-GLS test is performed by first estimating the intercept and trend utilizing the generalized least square technique. This estimation is investigated by generating the following variables:

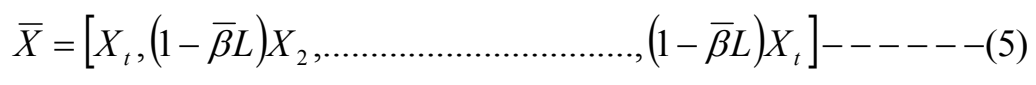

$$
\begin{aligned}
& \bar{Y}=\left[X_{t},(1-\bar{\beta} L) Y_{2}, \ldots \ldots \ldots \ldots \ldots \ldots \ldots \ldots \ldots \ldots \ldots,(1-\bar{\beta} L) Y_{t} \cdot\right]------(6) \\
& Y_{t}=(1, t) \bar{\beta}=1+\frac{\bar{\alpha}}{T}------------------------(7)
\end{aligned}
$$

\section{And}

Where "T" stands for number of observation of X variable and $\alpha$ is fixed. (Note 1)

While OLS estimation is followed by this equation:

$\bar{X}=\varphi_{0} \bar{Y}+\varphi_{1} Y_{t}+\varepsilon_{t}$

And OLS estimator's $\varphi_{0}$ and $\varphi_{1}$ are utilized for the removal of trend from as $X_{t}$ above. ADF test is employed on the transformed variables by fitting the OLS regression. (Note 2) 


$$
\Delta X_{t}^{d}=\lambda_{0}+\rho X_{t-1}^{d}+\sum_{j=1}^{k} \gamma_{j} \Delta X_{t-j}^{d}+u_{t}--------------(9)
$$

In alternative hypothesis, $\alpha=-7$ in the required equation of $\beta$, above, then they calculate $X_{t}^{d}=X_{t}-\varphi_{0}$, fit the ADF regression on new transformed variable and employ the test of the null hypothesis that is $\rho=0$.

In recent times, Ng-Perron (2001) developed four test statistics utilizing GLS de- trended data $D_{t}{ }^{d}$. the calculates values of theses tests based on forms of Philip -Perron (1988) $Z_{\alpha}$ and $Z_{t}$ statistics., the Bhargava (1986) $R_{1}$ statistics , and the Elliot, Rotherberg and Stock (1996) created optimal best statistics. The terms are defining as follows:

$k=\sum_{t=2}^{T}\left(D_{t-1}^{d}\right)^{2} / T^{2}$

While de-trend GLS tailored statistics are as given below:

$$
\begin{array}{cc}
M Z_{a}^{d}=\left(T^{-1}\left(D_{T}^{d}\right)^{2}-f_{0}\right) /(2 k) & M Z_{t}^{d}=M Z_{a} \times M S B \\
M S B=\left(k / f_{0}\right)^{1 / 2} & \text { and } \\
M P_{t}^{d}=\left\{c^{-2} k-c^{-} T^{-1}\left(D_{t}^{d}\right)^{2} / f_{0}\right. & \\
=\left\{c^{-2} k+\left(1-c^{-}\right) T^{-1}\left(D_{t}^{d}\right)^{2} / f_{0}\right.
\end{array}
$$

If $\mathrm{x}_{\mathrm{t}}=\{1\}$ in first case and $\mathrm{x}_{\mathrm{t}}=\{1, \mathrm{t}\}$ in second. (Note 3 )

\subsubsection{ARDL approach to Co-integration}

To examine the long run relationships between foreign exchange reserves and inflation rate in Pakistan, this study uses recent co-integration analysis approach, known as autoregressive-distributed lag (ARDL) model (Pesaran et al. (2001)\}. Pesaran et al. co-integration approach, is also known as Bounds testing technique. To begins with; we test for the null hypothesis of no co-integration against the existence of a long run relationship. Unlike other co integration techniques (e.g., Johansen's 1991) which require certain pre-testing for unit roots, that either our focused variables are integrated at the same order / level or not. All other techniques require the same level of Stationarity of variables for further process. But the ARDL model provides an substitute test for examining a long run relationship regardless of whether the underlying variables are $\mathrm{I}(0), \mathrm{I}(1)$, or fractionally integrated. This approach has the following econometric advantages in comparison to other Co-integration procedures.

1) The long and short-run parameters of the model in question are estimated simultaneously;

2) The ARDL approach to testing for the existence of a long-run relationship between the variables in levels is applicable irrespective of whether the underlying regressors are purely $I(0)$, purely $I(1)$, or fractionally integrated;

3) The small sample properties of the bounds testing approach are far superior to that of multivariate co-integration. The bounds testing approach of Pesaran et al. (2001) is employed to test the existence of a co-integration relationship among the variables.

4) Modified ARDL method is free from any problem faced by traditional techniques in the literature.

The Pesaran et al. procedure involves investigating the existence of a long-run relationship in the form of the unrestricted error correction model for each variable. According to ARDL procedure the unrestricted model of our concerned function will be as follow:

$$
\begin{aligned}
& \Delta \ln (G D P D)_{t}=\lambda_{0}+\sum_{i=1}^{n} \lambda_{i} \Delta \ln (G D P D)_{t-i}+\sum_{i=0}^{n} \lambda_{i} \Delta \ln (F E)_{t-i}+ \\
& \alpha_{1} \ln (G D P D)_{t-1}+\alpha_{2} \ln (F E)_{t-1}+v_{1 t}----------(11)
\end{aligned}
$$

Where $\ln ($ GDPD ) is the natural logarithms of Gross domestic product deflator, $\ln ($ FE ) is the natural logarithms of foreign exchange reserves, $\Delta$ is the difference operator and vi is the stochastic error term. To analyze the long run relationship existence we restrict the coefficients $\alpha_{1}$ and $\alpha_{2}$. The modified ARDL approach estimate ' $(\mathrm{n}+1)$ ' number of regression in order to obtain optimal lag length for each variable, where ' $n$ ' is the number of lags to be used in the equation\#11. The null hypothesis which we develop for investigation of long run is as follow:

$$
H_{0}=\alpha_{1}=\alpha_{2}=0
$$


The F-test is used to test the existence of long-run relationships. Thus; the Pesaran et al. approach compute two sets of critical values for a given significance level. One set assumes that all variables are $I(0)$ and the other set assumes they are all $I(1)$. If the computed F-statistic exceeds the upper critical bounds value, then the $H_{0}$ (null hypothesis) is rejected. If the F-statistic falls into the bounds, then the test becomes inconclusive. Lastly, if the F-statistic is below the lower critical bounds value, it implies no co-integration. When long-run relationship exists, the F-test indicates which variable should be normalized.

Moreover, when the order of integration of the variables is known and if all the variables are $I(1)$,then the decision is based on the upper bound value. Similarly, if all the variables are $I(0)$,then the decision is based on the lower bound. After estimation of long run relationship by employing the selected ARDL model, there is variety of diagnostic and stability tests, and utilization of these tests in turn enhance the credibility of regressed model. These diagnostic tests examine the serial correlation, functional form, normality and heteroscedasticity associated with model.

\section{Empirical Examination and Analysis.}

\subsection{Unit Root Problem and Co-integration analysis}

To investigate the order of integration we relied on the ADF (Augmented Dicky Fuller) and more reliable test especially for small size data is DF-GLS (Dicky Fuller Generalized Least Square) tests. The statistics of DF-GLS usually considered more power full than other test like ADF etc. But here we find that both tests give us the same results. Statistics of both tests are given in the tables \# $1 \& 2$ arranged in the end of paper. According to both unit root process (which investigate the order where our focused variables are stationary) results reveals that the both our given variables are stationary at first difference and at $1 \%$ level of significance. After this clarity that our variables are stationary at first difference we used the ARDL (Autoregressive Distributive Lag Model) by Pesaran (2001) to inquire the existence of co-integration either in long run or in short span of time. The results of ARDL co-integration test are presented in table \#3 given in the end of paper. Here our assumed null hypothesis is "Existence of no co-integration between inflation rate (ln GDPD) and foreign exchange reserves (ln FE)" but our trace/calculated t value of foreign exchange reserves variable is -4.0037 , has zero probability of acceptance of our proposed null hypothesis of no co-integration. Hence we reject our null hypothesis in the favor of alternative hypothesis and conclude that there is existence of co-integration between our focused variables. Results reveals like other economies that foreign exchange reserves also affect the rate of inflations in Pakistan. We used the Measure of goodness of fit, Adjusted R square, Durbin Watson and all other results of F and LM diagnostic tests to enhance the credibility of our empirical results of co-integration. LM \&F tests results clearly indicate the correct functional form, no presence of autocorrelation and heteroscedasticity, in our regressed line. So we strongly conclude that long run relationship exist between inflation and foreign exchange level in Pakistan during study period.

\section{2 long Run and Short Run Dynamics Behaviors}

As we observed that our targeted variables foreign exchange reserves and inflation rate exhibit the long run connection between one and other. To investigate the intensity of such relationships we regressed the equation. Table 4 given in the end of paper shows the results of long run coefficient. This table describes the long run elasticity because all variables are in logarithm form. Estimation shows that Foreign Exchange reserves (FE) has negative and significant affect on rate of inflation in Pakistan in long span of time. No doubt elasticity of inflation with respect to change in levels of foreign exchange reserves in Pakistan is very low, but impacts of change in foreign exchange reserves on inflation rate are not ignorable. Because $t$ ratio of foreign exchange reserves coefficient not only statistically significant but also has zero probability of acceptance of null hypothesis of no long run relationship between foreign exchange reserves and inflation rate in Pakistan. Lagged values of GDP deflator with difference 1 and 2 also have positive and significant impact on inflation in Pakistan. The reliability of our long run regressed function improved by the sound and stable diagnostic tests like, measure of goodness of fit, Adjusted R square, Durbin Watson d statistics, LM and $\mathrm{F}$ tests of autocorrelation, heteroscedasticity, and correct functional form of our regressed line . LM \&F tests results clearly indicate the no presence of autocorrelation, and heteroscedasticity. Coefficient of determination is close to unity with significant $\mathrm{F}$ ratio. It is true that D.W. statistics is meaning less in the presence of lagged values of dependent variable as explanatory variable but it will be compensated by diagnostic test of serial correlation. This is indicating the no auto/serial correlation in data. Tests of correct functional form and heteroscedasticity are also satisfactory. So we may rely on our finding that foreign exchange reserves inversely and significantly affects the rate of inflation in Pakistan in long span of time.

Finally we employed the ECM version of modified ARDL to investigate the short run dynamic relationships. An important attribute of ARDL approach of estimation is, it provides the speed of correction if the dependent variable deviates from its steady state path due to uneven fluctuation of explanatory variables. All this will be done through the ECM (Error Correction Mechanism). We regressed the lagged value of inflation rate deputy on lagged value of our explanatory variable FE (foreign exchange reserves) with error correction variable at first difference as follow.

$$
\Delta \ln (G D P D)_{t}=\lambda_{0}+\sum_{i=1}^{n} \lambda_{i} \Delta \ln (G D P D)_{t-i}+\sum_{i=0}^{n} \lambda_{i} \Delta \ln (F E)_{t-i}+(E C M)_{t-1}------(12)
$$


Table \# 5 reports the results of ECM formulation of above given equation. According to Engle Granger (1987), co-integrated must have in ECM representation. As we state above here the ECM strategy will provides the answer of trouble if we found the spurious correlation in the short run dynamic relationship between Gross Domestic Product Deflator (proxy of inflation) and Foreign Exchange reserves. More technically, ECM measures the speed of adjustment back to co-integrated relationships. Here in estimation the signs of the short run dynamic impacts are maintained to the long span of time. The equilibrium correction coefficients estimated value is -0.133 (reported -0.13 ), which is significant and has correct sign also imply a fairly $13.3 \%$ per annum speed of correction if economy suffered with unexpected inflation due to uneven variations in foreign exchange reserves. In other words $13.3 \%$ disequilibrium (in inflation) from the previous year shock (in foreign exchange reserves) converges back to the long run equilibrium in the current year. Short run coefficient of determination and Durbin Watson statistics are also quite satisfactory

\section{Conclusion}

In this paper we have concluded the negative and significant relationship between foreign exchange reserves and inflation rate in Pakistan. This study has examined the empirical evidence through most reliable "ARDL" econometric technique. Our results are consistent with our hypothesis; our core explanatory variable "foreign exchange reserves" has negative and significant relationship with rate of inflation in Pakistan. The results differ from the earlier studies (most studies show the positive relationship between foreign exchange and inflation) on the following grounds.

1) Usually we expect the increase in reserves enhance the money supply which in turn raises the prices of commodities in general. But Pakistan's case is different than other developed, higher income developing countries and countries having more elastic imports. Pakistan's imports are based on food, crude oil, agriculture raw material, machinery and medicine etc. and all imports more or less rely on the foreign exchange reserves. Decline in the volume of foreign exchange reserves in turn reduces the imports of industrial and agricultural raw material ingredients immediately, and as a results supply shock enhances the price levels.

2) Less developed capital/ financial markets can not absorb even a slight change in reserves and ultimately there is a change in price levels, unless the national monetary authorities take appropriate actions to neutralize these foreign exchange changes.

3) Decline in foreign exchange reserves generates economic instability. Accordingly multinational companies reduce their business and as a result there is also a supply shock.

In broad terms our results here tend to defy the quantity theory of money, because here reductions in money supply via decline in foreign reserves augment the price level in general. So the finale of this story is; any short fall in foreign exchange reserves in Pakistan undoubtedly has some adverse effects on prices of goods and services, even though it may not be as strong as expected.

\section{References}

Ahmed, E. \& H. Ram. (1991). Foreign Price Shocks and Inflation in Pakistan: A Monetarist Approach. Pakistan Economic and Social Review, 29:1, pp.1-20

Bhargava, A. (1986). On the Theory of Testing for Unit Roots in Observed Time Series. Review of Economic Studies 53:3, 369-384.

Bilquees, F. (1988). Inflation in Pakistan : Empirical Evidences on the Monetarist and Structuralist Hypothesis. The Pakistan Development Review, 27:2 pp.109-130

Dejong N., Nankervis, J.C. \& Savin, N.E. (1992). Integration versus Trend Stationarity in Time Series. Econometrica, 60, 423-433.

Dickey, D. \& Fuller, W.A. (1979). Distribution of the Estimates for Autoregressive Time Series with Unit Root. Journal of the American Statistical Association, 74 (June), 427-31.

Eatzaz A. \& Saima A.Ali (1999). Exchange Rate and Inflation Dynamics. The Pakistan Development Reiview.38:3 pp.235-251.

Elliot, G., Rothenberg, T.J. \& Stock, J.H. (1996). Efficient Tests for an Autoregressive Unit Root. Econometrica, 64, 813-836.

Engle,R.F. \& C.W.J. Granger (1987). Co-integration and Error Correction Representation: Estimation and Testing. Econometrica 55,251-276.

Genberg, H. \& Alexander K. S. (1977). Worldwide Inflation under the Dollar Standard. Paper prepared for the SSRC-Ford Foundation Conference on " Macro Economic Policy and Adjustment in Open Economies" ,Ware, England, April 28-May1st 1976. Graduate Institute of International Studies, Discussion Paper No. 12 (Geneva,1977)

Haastrecht, A. V. \& Pelsser, A. (2008). Generic pricing of Foreign Exchange, Inflation and Stock options under Stochastic Interest rates and Stochastic volatility. Network for studies on Pensions, Aging and Retirement, Discussion Paper 10/2008 - 046, pp 1-45.

Harris, R. \& Sollis, R. (2003). Applied Time Series Modeling and Forecasting Wiley, West Sussex. 
Hassan, M.A. \& A.H. Khan. (1994). Impact of Devaluation on Pakistan's External Trade: An Econometric Approach. The Pakistan Development Review, 33:4, pp.1205-1215.

Heller, H. R. (1976).International Reserves and World-Wide Inflation. Staff Paper - International Monetary Fund. 23:1,61-87.

IFS May. (2007). published by International Monetary Fund.

Johansen, S. (1991). Estimation and Hypothesis Testing of Co-integrating Vectors in Gaussian Vector Autoregressive Models Econometrica. 59, pp.1551-1580.

Khan, M. A. \& A. Qayyum. (2007). Exchange Rate Determination in Pakistan: Evidence based on Purchasing Power Parity Theory. Pakistan Economic and Social Review, 45:2, 181-202.

Khan,A.H. \& M.A. Qasim. (1996). Inflation in Pakistan Revisited. The Pakistan Development Review, 35:4, pp.747-757.

Meiselman, D. I. (1975). Worldwide Inflation: A Monetarist View, In The Phenomenon of Worldwide Inflation, ed. by Meiselman and Arthur B. Laffer, American Enterprise Institute for Public Policy Research( Washington),69-112.

Mohsin, S. K. (1979). Inflation and International Reserves: A Time-Series Analysis. Staff Paper - International Monetary Fund.26:4, 699-724.

Ng, S. \& Perron, P. (2001). Lag Length Selection and the Construction of Unit Root Test with Good Size and Power. Econometrica, 69, 1519-1554.

Nieh, Chien-Chung. (2005). ARDL approach to the exchange rate overshooting inTaiwan. Review of Quantitive Finance and Accounting, Volume 25, pp. 55-71.

Parikh, A. \& G. Williams. (1998). Modelling real exchange rate behaviour: Across-country study. Applied Financial Economics, Volume 8, pp. 577-587.

Parkin M. (1977). A Monetarist Interpretation of the Generation and Transmission of World Inflation: 1958-71. American Economic Review, papers and Proceeding,67,164-171.

Pesaran M.H., Shin Y. \& Smith R.J. (2001). Bounds testing approaches to the analysis of level relationships. Journal of Applied Econometrics.16, 289-326.

Phillips, P.C.B. \& Perron, P. (1988). Testing for a unit root in Time series regression. Biometrica, 75, 335-446.

Prasertnukul, W., Kim, D. and Kakinaka, M. (2010). Exchange rates, Price levels, and Inflation targeting: Evidence from Asian countries. Economic development \& Policy series EDP 10 - 1, GSIR Working Paper, pp 1-34.

Rahman, M. H. \& M. I. Hossain. (2003). Exchange rate and investment in the manufacturing sector of Bangladesh. The Bangladesh Development Studies, Volume XXIX, Nos. 1 \&2, pp. 111-124.

Shahbaz et al. (2008). "Rural-Urban inequality under Finance and Trade Nexus: An Econometric Evidence" Paper in PSDE $23^{\text {rd }}$ Annual General Meeting and Conference.

Utami, S. T. and Inanga, E. L. (2009). Exchange rates, interest rates, and Inflation rates in Indonesia: The International Fisher Effect Theory. International Research Journal of Finance and Economics, Issue 26, pp 152-169.

\section{Notes}

Note 1. The power of envelop curve is one half at $\dot{\alpha}=-13.7$ when the model has contestant and trend term, and at $\dot{\alpha}=-7$ when it has only constant term (see Elliot et al., 1996 for comprehensive study)

Note 2. For the critical values (see Elliot et al., 1996) of null hypothesis which is $\rho=0$.

Note 3. See Shahbaz et al.(2008) "Rural -Urban inequality under Finance and Trade Nexus: An Econometric Evidence" Paper in PSDE $23^{\mathrm{RD}}$ Annual General Meeting and Conference.

\section{Times Series Data Unit Root Test Statistics}

Table 1. ADF Unit Root Test Statistics

\begin{tabular}{|c|c|c|c|c|c|c|}
\hline Variable & \multicolumn{3}{|c|}{ Level } & \multicolumn{3}{c|}{$1^{\text {st }}$ difference } \\
\hline & Inter. & Trend \& Inter. & None & Intercept & Trend \& Inter. & None \\
\hline GDPD $^{*}$ & 0.04 & -3.35 & 2.55 & $-4.03^{* *}$ & $-3.98^{* *}$ & -1.85 \\
\hline FE* $^{*}-0.41$ & -2.71 & 1.03 & $-6.98^{* *}$ & $-7.02^{* *}$ & 6.83 \\
\hline \multirow{3}{*}{ Critical Values } & L.O.S - & $1 \%$ & $5 \%$ & $10 \%$ \\
\cline { 4 - 7 } & & Intercept & -3.59 & -2.93 & -2.60 \\
\cline { 3 - 6 } & & Tr.\&Inter. & -4.17 & -3.51 & -3.18 \\
\cline { 3 - 6 } & & None & -2.62 & -1.95 & -1.61 \\
\hline
\end{tabular}

*Stands for natural $\log , * *$ Stands for ratio is significant at $1 \%$ 
Table 2. DF-GLS(Dicky Filler Generalized Least Square) Unit Root Test Statistics

\begin{tabular}{|c|c|c|c|c|c|}
\hline \multirow[t]{2}{*}{ Variable } & \multicolumn{2}{|c|}{ Level } & \multicolumn{3}{|c|}{$1^{\text {st }}$ difference } \\
\hline & Intercept. & Trend \& Inter & Intercept & \multicolumn{2}{|c|}{ Trend \& Inter. } \\
\hline GDPD* & 0.46 & -2.84 & $-3.87 * *$ & \multicolumn{2}{|c|}{$-4.06^{* *}$} \\
\hline FE* & -0.27 & -2.47 & $-6.37 * *$ & \multicolumn{2}{|c|}{$-7.09 * *$} \\
\hline \multirow{3}{*}{\multicolumn{2}{|c|}{ Critical Values }} & L.O.S $\longrightarrow$ & $1 \%$ & $5 \%$ & $10 \%$ \\
\hline & & Intercept & -2.62 & -1.94 & -1.61 \\
\hline & & Tr. \& Inter. & -3.77 & -3.19 & -2.89 \\
\hline
\end{tabular}

*Stands for natural $\log ,{ }^{*}$ Stands for ratio is significant at $1 \%$

Table 3. Autoregressive Distributed Lag Estimates

ARDL Co-integration Testing $(1,1)$ selected based on Schwarz Bayesian Criterion

\begin{tabular}{|c|c|c|c|c|}
\hline \multicolumn{5}{|c|}{ Dependent variable is GDPD, $\mathrm{n}=47$ (1961-07 ) } \\
\hline Regressors & Coefficient & Standard Error & F-Ratio & Prob. \\
\hline GDPD(-1) & 1.13 & 0.02 & 65.45 & 0.00 \\
\hline FE & 0.01 & 0.00 & -4.00 & 0.00 \\
\hline FE(-1) & 0.002 & 0.00 & 1.94 & 0.06 \\
\hline C & -0.18 & 0.46 & -0.38 \\
\hline R-Squared 0.99 & R-Bar-Squared 0.99 \\
\hline F-stat. F(3,43) 6117.4 & DW-statistic 2.13 \\
\hline
\end{tabular}

$\underline{\text { Diagnostic Tests }}$

\begin{tabular}{|c|c|c|c|c|c|c|c|}
\hline \multirow{2}{*}{$\#$} & \multirow{2}{*}{ Nature of Test } & \multicolumn{3}{|c|}{ LM Test } & \multicolumn{3}{c|}{ F Test } \\
\cline { 3 - 7 } & & Lags & Cal. Value & Prob. & df & Cal. Value & Prob. \\
\hline 1 & Serial Correlation & CHSQ(1) & 2.27 & 0.13 & $\mathrm{~F}(1,42)$ & 2.13 & 0.15 \\
\hline 2 & Functional Form & CHSQ(1) & 0.32 & 0.57 & $\mathrm{~F}(1,42)$ & 0.29 & 0.59 \\
\hline 3 & Heteroscedasticity & CHSQ(1) & 2.31 & 0.13 & $\mathrm{~F}(1,45)$ & 2.33 & 0.13 \\
\hline
\end{tabular}

Table 4. Estimated Long Run Coefficients

\begin{tabular}{|c|c|c|c|c|}
\hline Dependent variable is GDPD $\mathrm{n}=46$ (1962 -07) \\
\hline Regressor & Coefficient & Standard Error & T-Ratio & Prob. \\
\hline FE & -0.001 & 0.00 & -4.77 & 0.00 \\
\hline GDPD(-1) & 0.85 & 0.14 & 6.01 & 0.00 \\
\hline GDPD(-2) & 0.33 & 0.16 & 2.04 & 0.05 \\
\hline C & -0.29 & 0.48 & -0.59 & 0.55 \\
\hline R-Squared 0.99 & R-Bar-Squared 0.99 \\
\hline F-stat. F(3,43) 5937 & DW-statistic 2.10 \\
\hline
\end{tabular}

$\underline{\text { Diagnostic Tests }}$

\begin{tabular}{|c|l|c|c|c|c|c|c|}
\hline$\#$ & \multirow{2}{*}{ Nature of Test } & \multicolumn{3}{|c|}{ LM Test } & \multicolumn{3}{c|}{ F Test } \\
\cline { 3 - 8 } & & Lags & Cal. Value & Prob. & df & Cal. Value & Prob. \\
\hline 1 & Serial Correlation & CHSQ(1) & 1.37 & 0.24 & $\mathrm{~F}(1,41)$ & 1.26 & 0.27 \\
\hline 2 & Functional Form & CHSQ(1) & 0.05 & 0.82 & $\mathrm{~F}(1,41)$ & 0.04 & 0.84 \\
\hline 3 & Heteroscedasticity & CHSQ(1) & 4.62 & 0.03 & $\mathrm{~F}(1,44)$ & 4.92 & 0.13 \\
\hline
\end{tabular}

Table 5. Short Run Estimates

\begin{tabular}{|c|c|c|c|c|}
\hline Dependent variable is $\Delta$ GDPD, $\mathrm{n}=47$ (1961-07) \\
\hline Regressor & Coefficient & Standard Error & T-Ratio & Prob. \\
\hline$\Delta(\mathrm{FE})$ & -0.01 & 0.00 & -4.00 & 0.00 \\
\hline $\mathrm{C}$ & -0.18 & 0.46 & -0.38 & 0.71 \\
\hline ECM(-1) & -0.13 & 0.02 & -7.70 & 0.00 \\
\hline R-Squared 0.68 & R-Bar-Squared 0.65 \\
\hline F-stat. F(3,43) 29.46 & DW-statistic 2.10 \\
\hline
\end{tabular}

